\title{
Obstetric and perinatal outcomes in pregnancies occurring as a result of Fresh and Thawed frozen embryo transfer
}

\author{
Nishita Shah*, K. Jayakrishnan \\ Department of Obstetrics and Gynecology, KJK Hospital, Fertility Research and Gynec Center, Trivandrum, Kerala, \\ India
}

Received: 02 May 2019

Accepted: 09 July 2019

*Correspondence:

Dr. Nishita Shah,

E-mail: nkdesai.89@gmail.com

Copyright: $\odot$ the author(s), publisher and licensee Medip Academy. This is an open-access article distributed under the terms of the Creative Commons Attribution Non-Commercial License, which permits unrestricted non-commercial use, distribution, and reproduction in any medium, provided the original work is properly cited.

\begin{abstract}
Background: In vitro fertilization is a known independent risk factor for adverse perinatal outcomes. To explore obstetric and perinatal outcomes in pregnancies occurring as a result of fresh and thawed frozen embryo transfer.

Methods: Retrospective observational study with 208 patients. A period of 2 years from October 2015 to October 2017. Tertiary care Fertility, Laparoscopy and research centre. All pregnancies conceived by IVF $(n=208)$ between the study period were included. The patients were grouped by fresh $(n=108)$ versus frozen $(n=100)$ embryo transfer. Patients conceived with donor embryo transfer were excluded. Primary outcomes were missed abortions, ectopic pregnancy, live births. Incidence singleton pregnancies and multiple gestations, preterm delivery, birth weight, an obstetric complication includes gestational hypertension, preeclampsia, gestational DM, placenta previa.

Results: A total 208 patient analyzed who conceived with IVF treatments, among them 108 patients were in Fresh ET group and 100 were in Frozen ET group. The incidence of Ectopic Pregnancy was more in fresh ET as compared to Frozen ET $(14.8 \%, 02 \%$ respectively, p value $<0.05)$ whereas that of missed abortions were more in Frozen ET $(22 \%$ versus $11.1 \%$, $\mathrm{p}$ value 0.03 ). There were no significant differences in obstetric and perinatal outcomes in both groups. Conclusions: In this study of IVF pregnancies, adverse obstetric and neonatal outcomes did not differ between fresh and frozen embryo transfers. Literature tells that there may be an increased risk of preeclampsia and large for gestational age babies in pregnancies conceiving after frozen embryo transfer. So freeze all policy should be applied to only indicated cases and not to all because both the groups having similar outcomes.
\end{abstract}

Keywords: Ectopic pregnancy, Fresh and frozen ET, Missed Miscarriage, Obstetric and perinatal outcomes

\section{INTRODUCTION}

Since the birth of Louise Brown in 1978, more than 6 million babies have been born as a result of IVF and intra cytoplasmic sperm injection (ICSI). Today, nearly one in six couples faces fertility issues, as they fail to achieve a clinical pregnancy even after regular copulation., Consequently, couples are turning to assisted reproductive technology (ART) to become pregnant, which will hopefully result in the birth of a healthy baby. Conventionally, the aim has been to transfer the best- quality embryo or embryos in a fresh treatment cycle; any spare embryos are frozen for subsequent use. In 1983, the first frozen-thawed embryo was transferred by Trounson, which resulted in a successful pregnancy. ${ }^{3}$ Since then, continuous advancements in cryopreservation techniques have been made and at present, the quality and potential for frozen-thawed embryo implantation is comparable to those of fresh embryos. ${ }^{4,5}$

With refinement of technology in recent years, the numbers of thawed frozen embryo transfers have 
increased, as have pregnancy rates associated with them. ${ }^{6,7}$

Although fresh embryo transfer is still the norm in most in vitro fertilization (IVF) treatments, as it involves a shorter process that leads to pregnancy, this method is related to increased hormone levels due to controlled ovarian stimulation (COS). The supra-physiologic hormonal levels observed during COS results in a suboptimal uterine environment that may negatively impact embryo implantation and placentation, eventually culminating to untoward obstetrical and perinatal outcomes. ${ }^{8,9}$ Conversely, FET cultivates better environmental conditions within the uterus during embryo transfer, leading to improved endometrial receptivity. ${ }^{10,11}$ This better uterine environment may be related with better placentation during a FET cycle, leading to improved obstetric outcomes when compared to fresh transfer cycles. ${ }^{12,13}$

The knowledge concerning the differences in obstetrical and neonatal outcome between cryopreserved and fresh embryos is increasing. Literature suggests that the health of neonates born after FET is similar or even more favorable compared to the health of children born after fresh embryo transfer. ${ }^{14,15}$

Recent studies showed that neonates born after FET have decreased risks of preterm birth, LBW and being small for gestational age (SGA, below $10^{\text {th }}$ percentile) compared to fresh ET. ${ }^{12,14-17}$ An increased risk of high birth weight and being large for gestational age (LGA, above 90th percentile) was reported as well. ${ }^{14-18} \mathrm{~A}$ higher risk of congenital malformations for infants born after cryopreservation compared to fresh ET is also described. ${ }^{19,20}$

Recently published meta-analysis comparing obstetric outcomes in pregnancies after fresh and FET did not report major obstetric outcomes such as pregnancyinduced hypertension (PIH), pre-eclampsia, placenta previa, and placenta accreta. ${ }^{12,21}$ So we have done a retrospective observational study to evaluate obstetric and perinatal outcomes in pregnancies occurring as a result of fresh and thawed frozen embryo transfer.

\section{METHODS}

It is a retrospective observational study carried out at Tertiary care Fertility, Laparoscopy and research centre, between periods of 2 years from October 2015 to October 2017. Total 208 patients were included in the study.

\section{Inclusion criteria}

- All pregnancies conceived by IVF $(n=208)$ between the study period were included. The patients were grouped by fresh $(n=108)$ versus frozen $(n=100)$ embryo transfer.

\section{Exclusion criteria}

- Patients conceived with donor embryo, donor sperm and ovum donation were excluded from the study.

Missed miscarriage, ectopic pregnancy, live births were considered as primary outcomes and incidence singleton pregnancies and multiple gestations, preterm delivery, birth weight, obstetric complications includes gestational hypertension, preeclampsia, gestational DM, placenta previa were taken as secondary outcomes in the study.

\section{Statistical analysis}

For statistical analysis collected data was entered in MS Excel file. Descriptive statistics like frequency, percentage, mean, SD were calculated for summarizing data. Pearson's Chi-Square test was applied to check association between two categorical data. Logistic regression was run to estimate Fresh and Frozen Embryo Transfer. Throughout the result, significance level was set at $5 \%$.

\section{RESULTS}

Minimum age of the patients undergoing treatment was 22 years and maximum was 47 years with the mean age of 32 years.

Table 1 details the baseline characteristics between the two groups. Minimum age of the patients undergoing treatment was 22 year and maximum was 47 years with the mean age of 32 year. There was a statistically significant difference in the two groups in terms of women who underwent previous IVF treatment.

The proportion of women who had undergone previous treatment was significantly higher in the thawed frozen embryo transfer group (70\% versus $33.3 \%$ ). This is not surprising: thawed frozen embryos are generally transferred either after fresh embryo transfer is unsuccessful or for when a couple wishes to have a second baby using their pool of frozen embryos. Freeze all policy will be applied to only those patient who are at risk of OHSS, raised progesterone on the trigger day and endometrium less than $7 \mathrm{~mm}$ according to the protocol of our institution.

$61.1 \%$ of patient in fresh ET and $68 \%$ of patient in frozen ET were below 34 years of age. $72.2 \%$ cases of fresh ET and $75 \%$ cases on Frozen ET have primary infertility. 5 patients in fresh group and 3 patients in a frozen group had a previous live birth. In most of the cases in both the group two embryo were transferred. Average duration of infertility in fresh transfer group is 6.4 years and frozen group is 6.3 years. Most common indication of infertility treatment in fresh ET group was Male factor infertility while in Frozen group was PCOD. 
Table 1: Comparison of baseline characteristics.

\begin{tabular}{|c|c|c|c|c|}
\hline & & $\begin{array}{l}\text { Fresh embryo } \\
\text { transfer }(n=108)\end{array}$ & $\begin{array}{l}\text { Frozen embryo transfer } \\
(n=100)\end{array}$ & p-value \\
\hline \multirow[t]{5}{*}{ Age group } & $<=34$ & $66(61.1 \%)$ & $68(68 \%)$ & \multirow{5}{*}{0.779} \\
\hline & $35-37$ & $27(25 \%)$ & $19(19 \%)$ & \\
\hline & $38-39$ & $9(8.3 \%)$ & $7(7 \%)$ & \\
\hline & $40-42$ & $5(4.6 \%)$ & $4(4 \%)$ & \\
\hline & $>42$ & $1(0.9 \%)$ & $2(2 \%)$ & \\
\hline \multirow{2}{*}{ Previous IVF } & Yes & $36(33.3 \%)$ & $70(70 \%)$ & \multirow{2}{*}{$<0.001$} \\
\hline & No & $72(66.7 \%)$ & $30(30 \%)$ & \\
\hline \multirow{2}{*}{ Type of infertility } & Primary & $78(72.2 \%)$ & $75(75 \%)$ & \multirow{2}{*}{0.753} \\
\hline & Secondary & $30(27.8 \%)$ & $25(25 \%)$ & \\
\hline \multirow{2}{*}{ Previous live birth } & Yes & $5(4.6 \%)$ & $3(3 \%)$ & \multirow{2}{*}{0.723} \\
\hline & No & $103(95.4 \%)$ & $97(97 \%)$ & \\
\hline \multirow{3}{*}{$\begin{array}{l}\text { No of embryos } \\
\text { transferred }\end{array}$} & 1 & $2(1.9 \%)$ & $4(4 \%)$ & \multirow{3}{*}{0.160} \\
\hline & 2 & $92(85.2 \%)$ & $90(90 \%)$ & \\
\hline & $>=3$ & $14(13 \%)$ & $6(6 \%)$ & \\
\hline \multirow{4}{*}{$\begin{array}{l}\text { Duration of } \\
\text { infertility }\end{array}$} & $0-4$ & $33(30.6 \%)$ & $40(40 \%)$ & \multirow{4}{*}{0.478} \\
\hline & $5-9$ & $50(46.3 \%)$ & $39(39 \%)$ & \\
\hline & $10-14$ & $23(21.3 \%)$ & $18(18 \%)$ & \\
\hline & $15-20$ & $2(1.9 \%)$ & $3(3 \%)$ & \\
\hline \multirow{7}{*}{ Indications } & Tubal & $6(5.6 \%)$ & $6(6 \%)$ & \multirow{7}{*}{0.017} \\
\hline & Male Factor & $30(28 \%)$ & $26(26 \%)$ & \\
\hline & Unexplained & $19(17.8 \%)$ & $12(12 \%)$ & \\
\hline & Endometriosis & $15(14 \%)$ & $7(7 \%)$ & \\
\hline & PCOD & $23(21.5 \%)$ & $32(32 \%)$ & \\
\hline & Low AMH & $14(13.1 \%)$ & $9(9 \%)$ & \\
\hline & Others & $0(0 \%)$ & $8(8 \%)$ & \\
\hline
\end{tabular}

Table 2: Live birth rate.

\begin{tabular}{|c|c|c|c|c|c|}
\hline & & \multicolumn{2}{|l|}{ Group } & \multirow[b]{2}{*}{$\begin{array}{l}\text { Total } \\
(N=208)\end{array}$} & \multirow[b]{2}{*}{ P-value } \\
\hline & & $\begin{array}{l}\text { Fresh embryo transfer } \\
(\mathrm{N}=100)\end{array}$ & $\begin{array}{l}\text { Frozen embryo transfer } \\
(N=108)\end{array}$ & & \\
\hline \multirow{4}{*}{ Live Birth } & \multirow{2}{*}{ Yes } & 67 & 67 & 134 & \multirow{4}{*}{0.455} \\
\hline & & $62.0 \%$ & $67.0 \%$ & $64.4 \%$ & \\
\hline & \multirow{2}{*}{ No } & 41 & 33 & 74 & \\
\hline & & $38.0 \%$ & $33.0 \%$ & $35.6 \%$ & \\
\hline
\end{tabular}

Table 3: Ectopic pregnancy.

\begin{tabular}{|c|c|c|c|c|c|c|c|}
\hline & & Group & & & & & \\
\hline & & $\begin{array}{l}\text { Fresh embryo } \\
\text { transfer }\end{array}$ & $\begin{array}{l}\text { Frozen embryo } \\
\text { transfer }\end{array}$ & Total & & & \\
\hline \multirow{4}{*}{$\begin{array}{l}\text { Ectopic } \\
\text { pregnancy }\end{array}$} & \multirow[b]{2}{*}{ Yes } & 16 & 2 & 18 & & & \\
\hline & & $14.8 \%$ & $2.0 \%$ & $8.7 \%$ & $\begin{array}{l}\text { Pearson CHI-Square Test } \\
\text { Value }\end{array}$ & df & $\mathrm{P}$ - value \\
\hline & \multirow{2}{*}{ No } & 92 & 98 & 190 & \multirow{4}{*}{10.787} & \multirow{4}{*}{1} & \multirow{4}{*}{0.001} \\
\hline & & $85.2 \%$ & $98.0 \%$ & $91.3 \%$ & & & \\
\hline \multirow{2}{*}{ Total } & & 108 & 100 & 208 & & & \\
\hline & & $100.0 \%$ & $100.0 \%$ & $100.0 \%$ & & & \\
\hline
\end{tabular}

In recent years, a freeze-all strategy has been suggested as a way to further improve IVF outcomes. By adopting this strategy, the potential deleterious effects of controlled ovarian stimulation (COS) on the endometrium 
could be avoided, and better results would be obtained. Live birth in fresh group was $62 \%$ and in frozen group was $67 \%$. Table 2 suggesting that there is no significant difference in the live birth rate in both the groups ( $\mathrm{P}$ value 0.45$)$.

Table 3 showing ectopic pregnancy was found significantly more in fresh ET group as compared to Frozen ET. (14.8\% versus $2 \%$, p-value 0.001$)$. It was observed that the subfertility requiring ART treatment is one of the independent risk factors for ectopic pregnancy. Among pregnancies following ART treatment, the reproductive health characteristics of women including tubal factor subfertility, endometriosis, previous pelvic inflammatory disease and previous ectopic pregnancy history have been identified as the most prominent risk factors for ectopic pregnancy.

Table 4: Missed miscarriage.

\begin{tabular}{|l|llll|}
\hline & Fresh embryo transfer $(\mathrm{n}=\mathbf{1 0 8})$ & Frozen embryo transfer $(\mathrm{n}=100)$ & $\mathrm{p}$-value & $\mathrm{RR}$ \\
Missed miscarriage & $12(11.1 \%)$ & $22(22 \%)$ & 0.034 & 0.640 \\
\hline
\end{tabular}

Table 5: Obstetric outcomes of fresh and frozen ET.

\begin{tabular}{|lllll|}
\hline & Fresh embryo transfer $(\mathbf{n}=\mathbf{1 0 8})$ & Frozen embryo transfer $(\mathbf{n}=\mathbf{1 0 0})$ & $\mathbf{p}$-value & RR \\
\hline PIH & $12(11.1 \%)$ & $14(14 \%)$ & 0.529 & 0.565 \\
\hline Preeclampsia & $4(3.7 \%)$ & $6(6 \%)$ & 0.439 & 0.762 \\
\hline GDM & $21(19.4 \%)$ & $18(18 \%)$ & 0.790 & 1.046 \\
\hline Placenta previa & $4(3.4 \%)$ & $0(0 \%)$ & 0.052 & 1.962 \\
\hline PPROM & $8(7.4 \%)$ & $8(8 \%)$ & 0.873 & 0.960 \\
\hline
\end{tabular}

Table 6: Neonatal outcomes.

\begin{tabular}{|c|c|c|c|c|c|c|}
\hline & & $\begin{array}{l}\text { Fresh embryo } \\
\text { transfer }(n=67)\end{array}$ & $\begin{array}{l}\text { Frozen embryo } \\
\text { transfer }(n=67)\end{array}$ & $\begin{array}{l}\text { p- } \\
\text { value }\end{array}$ & $\begin{array}{l}\text { Un standardized } \\
\text { OR }\end{array}$ & $\begin{array}{l}\text { Accuracy in } \\
\text { prediction }\end{array}$ \\
\hline \multirow{2}{*}{ BW } & Normal & $42(62.7 \%)$ & $37(55.2 \%)$ & \multirow{2}{*}{0.380} & 1 & \multirow{2}{*}{$53.7 \%$} \\
\hline & LBW & $25(37.3 \%)$ & $30(44.8 \%)$ & & 1.362 & \\
\hline \multirow{3}{*}{$\begin{array}{l}\text { Gestational } \\
\text { age (wk) }\end{array}$} & Normal & $48(71.6 \%)$ & $46(68.7 \%)$ & \multirow{3}{*}{0.475} & 1 & \multirow{3}{*}{$55 \%$} \\
\hline & Preterm & $16(23.9 \%)$ & $20(29.9 \%)$ & & 1.304 & \\
\hline & Very preterm & $3(4.5 \%)$ & $1(1.5 \%)$ & & 0.348 & \\
\hline
\end{tabular}

Table 4 indicate that rate of missed miscarriage is found to be more in frozen ET group. 12 cases in the fresh ET and 22 cases in the frozen ET group were ended in Missed Miscarriage which was statistically significant.

Table 5 showing obstetric complications in both the groups. Gestational hypertension was found in $14 \%$ of the cases in frozen ET while only in $11 \%$ in fresh ET. Preeclampsia also found more in frozen ET as compared to fresh ET though statistically not significant. GDM found in 21 cases as compared to 18 cases in both groups respectively.

Preterm delivery was defined as the delivery before 37 completed weeks of gestation. There was no statistical difference in the risk of preterm delivery in pregnancies occurring as a consequence of thawed frozen embryo transfer in comparison with those following fresh embryo transfers as shown in table 6. (29.9\% versus $23.9 \%$, pvalue 0.47 ). Low birth weight is considered when birth weight is less than $2.5 \mathrm{~kg}$. While comparing two groups there was no statistical difference found. (37.3\% in fresh
ET versus $44.8 \%$ in frozen ET, p- value 0.38). Mean birth weight in fresh ET is $2.51 \mathrm{~kg}$ and in frozen ET is $2.33 \mathrm{~kg}$.

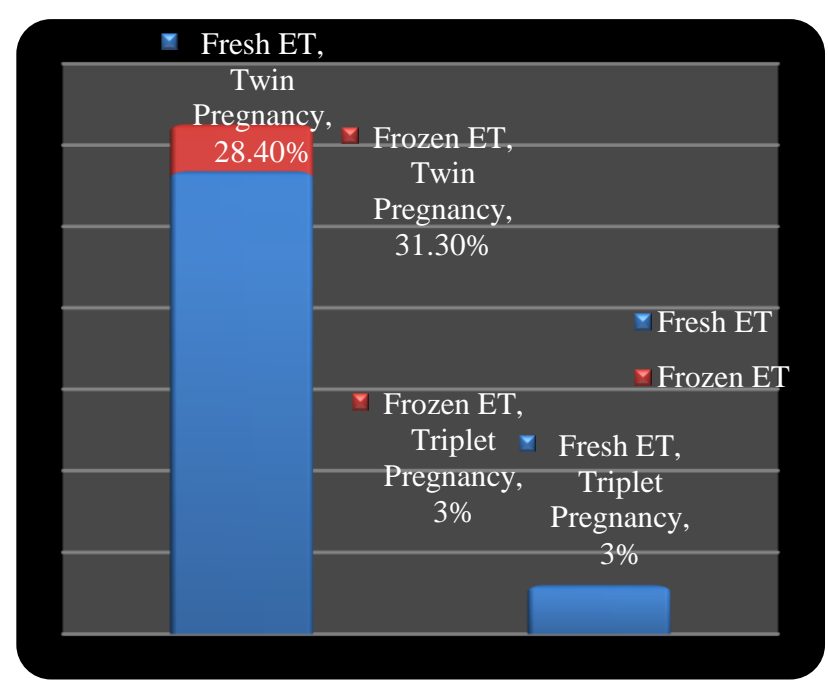

Figure 1: Multiple pregnancy. 
Figure 1 showing the incidence of multiple pregnancy in both the group. Frozen ET group has slightly raised proportion of twin gestation though not statistically significant $(31.30 \%$ versus $28.40 \%$, p-value 0.93$) .20$ babies in the fresh and 25 in the frozen group required NICU admission after delivery seen in Figure 2.

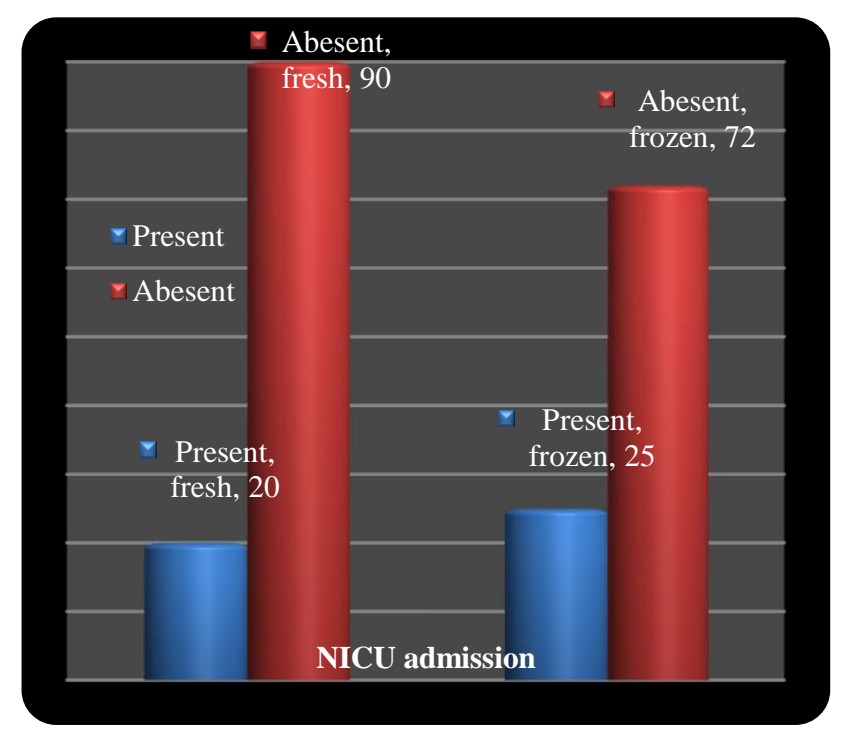

Figure 3: NICU admission.

\section{DISCUSSION}

In this study, we have done a retrospective analysis of the effect of FET and fresh embryo transfer on the risks of developing major obstetric and neonatal complications in pregnancies following the use of ART.

The main outcome of the study is there is no significant difference in live birth rate in both the group. Incidence of ectopic pregnancy found significant in fresh ET group and missed miscarriage found in frozen group.

A retrospective cohort study of 13426 cycles comparing live birth rate after fresh or frozen-thawed embryo transfers in relation to maternal age conclude that in every age-group, frozen cleavage-stage embryo transfers had lower LBR than that of fresh cleavage-stage embryo transfers. $^{22}$

Another study comparing fresh and frozen embryo cycles showing that fresh embryo transfer cycles were associated with improved clinical pregnancy and live birth rates compared to previously frozen embryo transfer cycles. The miscarriage rate and the multiple pregnancy rates were similar in both groups. ${ }^{23}$

A single-center, randomized, controlled trial, assigned 782 infertile women without the polycystic ovary syndrome into fresh and frozen embryo transfer group conclude that the transfer of frozen embryos did not result in significantly higher rates of ongoing pregnancy or live birth than the transfer of fresh embryos. ${ }^{3}$ this results are similar to our study. ${ }^{24}$

Retrospective historical cohort study conducted to evaluate whether the uterine environment is associated with the risk of ectopic implantation by comparing outcomes of fresh and frozen-thawed embryo transfers found that Embryo transfers in frozen cycle, were associated with lower rates of Ectopic pregnancy compared with fresh autologous cycles, suggesting that a difference in the tubal-uterine environment contributes to abnormal implantation after IVF. ${ }^{25}$

The increased risk of Ectopic pregnancy after fresh embryo transfers with autologous oocytes may be related to the effect of supraphysiologic hormonal levels on uterine contractility or endometrial receptivity. ${ }^{26-31}$ Another possible mechanism may be related to multifollicular ovulation and the oocyte retrieval procedure itself, which could contribute to both uterine contractility and release of implantation mediators adjacent to the fallopian tube. ${ }^{32,33}$ The role of inflammation in ectopic pregnancy is also well known, and could help explain our findings of Increased odds of EP in fresh ET group.

There is no significant difference in obstetric complications in both the groups in our study.

A systematic review and meta-analysis on Obstetric outcomes after fresh versus frozen-thawed embryo Transfers searched 654 papers and showing that when comparing pregnancies that arose from FET or fresh embryo transfer, there was an increase in the risk of obstetric complications in pregnancies resulting from FET when compared to those emerging from fresh embryo transfers in PIH (aOR 1.82; 95\% CI 1.24-2.68), pre-eclampsia (aOR 1.32, 95\% CI 1.07, 1.63), and placenta accreta (aOR 3.51, 95\% CI 2.04-6.05). ${ }^{34}$

A retrospective cohort study compared the frequency of preeclampsia diagnosis for cryopreserved-warmed versus fresh ET in 15,937 births from ART found that Among pregnancies conceived with autologous eggs resulting in singletons, preeclampsia was greater after cryopreservedwarmed versus fresh ET $(7.51 \%$ versus $4.29 \%$, adjusted odds ratio $=2.17$ [95\% CI 1.67-2.82]) and among twin pregnancies, the frequency of preeclampsia with severe features $(9.26 \%$ versus $5.70 \%)$ and preeclampsia with preterm delivery $(14.81 \%$ versus $11.74 \%)$ was higher after cryopreserved versus fresh transfers. ${ }^{35}$ In our study also gestational hypertension and preeclampsia were found more in Frozen ET group though statistically not significant.

Low levels of E2 in early primate pregnancy allow for migration of extravillous trophoblasts into uterine spiral arteries with artery remodelling; elevation of E2 later in pregnancy prevents further remodelling. If E2 is elevated prematurely, extravillous trophoblast invasion of spiral 
arteries is suppressed. It is possible that prematurely cryopreserved-warmed transfers may contribute to more frequent preeclampsia in ART pregnancies compared with spontaneous conceptions. ${ }^{35}$

In our study there is no significant difference in the neonatal outcomes when comparing both groups. But recent studies found that there is a higher risk of large for gestational age babies after FET. A recent retrospective cohort study to explore obstetric and perinatal outcomes in singleton pregnancies in fresh and Frozen ET group conclude that the findings of low birth and very low birth weight after thawed frozen embryo transfer are consistent with the literature but they highlight the possibility of high birth weight in this babies. ${ }^{36}$ In our study we didn't found any significant difference in the birth weight in both the groups.

\section{CONCLUSION}

In this study of IVF pregnancies, adverse obstetric and neonatal outcomes did not differ between fresh and frozen embryo transfers. Literature tells that there may be an increased risk of preeclampsia and large for gestational age babies in pregnancies conceiving after frozen embryo transfer. So freeze all policy should be applied to only indicated cases and not to all because both the groups having similar outcomes.

Funding: No funding sources

Conflict of interest: None declared

Ethical approval: The study was approved by the Institutional Ethics Committee

\section{REFERENCES}

1. Boivin J, Bunting L, Collins JA, Nygren KG. International estimates of infertility prevalence and treatment-seeking:potential need and demand for infertility medical care. Hum Reprod. 2007;22:150612.

2. Zegers-Hochschild F, Adamson GD, de Mouzon J, Ishihara O, Mansour R, Nygren K, et al. International committee for monitoring assisted reproductive technology; world health organization. international committee for monitoring assisted reproductive technology (ICMART) and the World Health Organization (WHO) revised glossary of ART terminology. Fertil Steril. 2009;92:1520-4.

3. Trounson A, Mohr L. Human pregnancy following cryopreservation, thawing and transfer of an eightcell embryo. Nature. 1983;305:707-9.

4. Herrero L, Martinez M, Garcia-Velasco JA. Current status of human oocyte and embryo cryopreservation. Curr Opin Obstet Gynecol. 2011;23:245-50.

5. Shapiro BS, Daneshmand ST, Garner FC, Aguirre M, Hudson C, Thomas S. Similar ongoing pregnancy rates after blastocyst transfer in fresh donor cycles and autologous cycles using cryopreserved bipronuclear oocytes suggest similar viability of transferred blastocysts. Fertil Steril. 2010;93:319-21.

6. Dyer S, Chambers GM, de Mouzon J, Nygren KG, Zegers-Hochschild F, Mansour R, et al. International Committee for Monitoring Assisted Reproductive Technologies world report: Assisted Reproductive Technology 2008, 2009 and 2010. Hum Reprod. 2016;31:1588-609.

7. Roque M, Lattes K, Serra S, Sol_a I, Geber S, Carreras R, et al. Fresh embryo transfer versus frozen embryo transfer in vitro fertilization cycles: a systematic review and meta-analysis. Fertil Steril. 2012;99:156-62.

8. Mainigi M, Rosenzweig JM, Lei J, Mensah V, Thomaier L, Talbot CC, et al. Peri-implantation hormonal milieu: elucidating mechanisms of adverse neurodevelopmental outcomes. Reprod Sci. 2016;23:785-94.

9. Imudia AN, Awonuga AO, Doyle JO, Kaimal AJ, Wright DL, Toth TL, et al. Peak serum estradiol level during controlled ovarian hyperstimulation is associated with increased risk of small for gestational age and preeclampsiain singleton pregnancies after in vitro fertilization. Fertil Steril. 2012;97:1374-9.

10. Barnhart KT. Introduction: are we ready to eliminate the transfer of fresh embryos in vitro fertilization? Fertil Steril. 2014;102:1-2.

11. Weinerman R, Mainigi M. Why we should transfer frozen instead of fresh embryos: the translational rationale. Fertil Steril. 2014;102:10-8.

12. Maheshwari A, Pandey S, Shetty A, Hamilton M, Bhattacharya S. Obstetric and perinatal outcomes in singleton pregnancies resulting from the transfer of frozen thawed versus fresh embryos generated through in vitro fertilization treatment: a systematic review and meta-analysis. Fertil Steril. 2012;98:36877.e1-9.

13. Roque M, Valle M, Guimarães F, Sampaio M, Geber S. Freeze-all policy: fresh vs. frozen-thawed embryo transfer. Fertil Steril. 2015b;103:1190-3.

14. Pinborg A, Loft A, Aaris Henningsen AK, Rasmussen S, Andersen AN. Infant outcome of 957 singletons born after frozen embryo replacement: the Danish National Cohort Study 1995-2006. Fertil Steril. 2010;94:1320-7.

15. Pelkonen S, Koivunen R, Gissler M, NuojuaHuttunen S, Suikkari AM, Hydén-Granskog C, et al: Perinatal outcome of children born after frozen and fresh embryo transfer: the Finnish cohort study 19952006. Hum Reprod. 2010;25:914-23.

16. Li Z, Wang YA, Ledger W, Edgar DH, Sullivan EA. Clinical outcomes following cryopreservation of blastocysts by vitrification or slow freezing: a population-based cohort study. Hum Reprod. 2014;29:2794-801.

17. Wennerholm UB, Henningsen AK, Romundstad LB, Bergh C, Pinborg A, Skjaerven R, et al. Perinatal outcomes of children born after frozen-thawed embryo transfer: a Nordic cohort study from the CoNARTaS group. Hum Reprod. 2013;28:2545-53. 
18. Sazonova A, Källen K, Thurin-Kjellberg A, Wennerholm UB, Bergh C. Obstetric outcome in singletons after in vitro fertilization with cryopreserved/thawed embryos. Hum Reprod. 2012;27:1343-50.

19. Pelkonen S, Hartikainen AL, Ritvanen A, Koivunen R, Martikainen H, Gissler M, et al. Major congenital anomalies in children born after frozen embryo transfer: a cohort study 1995-2006. Hum Reprod. 2014;29:1552-7.

20. Belva F, Henriet S, Van den Abbeel E, Camus M, Devroey P, Van der Elst J, et al. Neonatal outcome of 937 children born after transfer of cryopreserved embryos obtained by ICSI and IVF and comparison with outcome data of fresh ICSI and IVF cycles. Hum Reprod. 2008;23:2227-38.

21. Pinborg A, Wennerholm UB, Romundstad LB, Loft A, Aittomaki K, Söderström-Anttila V, et al. Why do singletons conceived after assisted reproduction technology have adverse perinatal outcome? Systematic review and meta-analysis. Hum Reprod Update. 2013;19:87-104.

22. Li X. Live birth rate after fresh or frozen-thawed embryo transfers in relation to maternal age: a retrospective cochort study of 13426 cycles. Fertil Steril. 2016;106(3):e142.

23. Abdalmageed OS. Comparison of fresh versus previously frozen embryo transfer in women with polycystic ovary syndrome. Fertil Steril. 2016:106(3):e256-e257.

24. Vuong LN, Dang VQ, Ho TM, Huynh BG, Ha DT, Pham TD, et al. IVF transfer of fresh or frozen embryos in women without polycystic ovaries. N Engl J Med 2018 Jan 11;378(2):137-47.

25. Londra L, Moreau C, Strobino D, Garcia J, Zacur H, Zhao Y. A ectopic pregnancy after in vitro fertilization: differences between fresh and frozenthawed cycles, Fertil Steril. 2015;104:110-8.

26. Mueller A, Siemer J, Schreiner S, Koesztner H, Hoffmann I, Binder $\mathrm{H}$, et al. Role of estrogen and progesterone in the regulation of uterine peristalsis: results from perfused nonpregnant swine uteri. Hum Reprod. 2006;21:1863-8.

27. Fanchin R, Ayoubi JM, Olivennes F, Righini C, de Ziegler D, Frydman R. Hormonal influence on the uterine contractility during ovarian stimulation. Hum Reprod. 2000;15(Suppl 1):90-100.

28. Pal L, Jindal S, Witt BR, Santoro N. Less is more: increased gonadotropin use for ovarian stimulation adversely influences clinical pregnancy and live birth after in vitro fertilization. Fertil Steril. 2008;89:1694701 .

29. Martinez-Conejero JA, Simon C, Pellicer A, Horcajadas JA. Is ovarian stimulation detrimental to the endometrium? Reprod Biomed. 2007;15:45-50.

30. Horcajadas JA, Riesewijk A, Polman J, van Os R, Pellicer A, Mosselman S, et al. Effect of controlled ovarian hyperstimulation in IVF on endometrial gene expression profiles. Mol Hum Reprod. 2005;11:195205.

31. Macklon NS, van der Gaast MH, Hamilton A, Fauser BC, Giudice LC. The impact of ovarian stimulation with recombinant FSH in combination with GnRH antagonist on the endometrial transcriptome in the window of implantation. Reprod Sci. 2008;15:35765.

32. Espey LL. Ovulation as an inflammatory reaction: a hypothesis. Biol Reprod. 1980;22:73-106.

33. Bukulmez O, Arici A. Leukocytes in ovarian function. Hum Reprod Update. 2000;6:1-15.

34. Roque M, Valle M, Sampaio M, Geber S. Obstetric outcomes after fresh versus frozen-thawed embryo transfers: a systematic review and meta-analysis. JBRA Assisted Reproduct. 2018;22(3):253-60.

35. Cynthia K. Embryo cryopreservation and preeclampsia risk Sites. Fertil Steril. 2016;108(5):784-90.

36. Maheshwari, Abha. Obstetric and perinatal outcomes after either fresh or thawed frozen embryo transfer: an analysis of 112,432 singleton pregnancies recorded in the human fertilisation and embryology authority anonymized dataset. Fertil Steril. 2016;106(7):1703-8.

Cite this article as: Shah N, Jayakrishnan K. Obstetric and perinatal outcomes in pregnancies occurring as a result of Fresh and Thawed frozen embryo transfer. Int J Reprod Contracept Obstet Gynecol 2019;8:3311-7. 